Article

\title{
Desiliconisation and Dephosphorisation Behaviours of Various Oxygen Sources in Hot Metal Pre-Treatment
}

\author{
Youngjo Kang \\ Department of Material Science and Engineering, Dong-A University, Saha-gu, Busan 48315, Korea; \\ youngjok@dau.ac.kr; Tel.: +82-51-200-7758
}

Received: 25 January 2019; Accepted: 17 February 2019; Published: 20 February 2019

\begin{abstract}
In order to obtain a better understanding of the efficiencies of desiliconisation and dephosphorisation reactions during hot metal pretreatment in an open ladle, a number of simulation experiments were carried out with various oxygen sources. Three types of solid oxygen materials (sintered return ore, scale briquette and fine mill scale) were carefully investigated as hot metal pre-treatment agents, evaluating their desiliconisation and dephosphorisation efficiencies. The method applied for supplying gaseous oxygen was also assessed. The comparison between top blowing and injection methods indicated that injected oxygen gas is more advantageous for desiliconisation, while top-blown oxygen gas is favourable for dephosphorisation. The obtained information on the characteristics of gaseous oxygen can be used for the optimisation of blowing patterns, in order to improve the efficiency of the hot metal pre-treatment.
\end{abstract}

Keywords: hot metal pre-treatment; desiliconisation; dephosphorisation; solid and gaseous oxygen

\section{Introduction}

Steelmaking based on blast furnaces has been dominant for many years, due to its high productivity and low cost. However, due to the presence of considerable amounts of impurities (such as C, S, P and Si) in the hot metal from blast furnaces, a careful refinement must be carried out to obtain final products with acceptable properties. In order to reduce the burden in the refining of the converter in the conventional process, the hot metal pre-treatment technique (originally developed in Japan) has been improved over several decades, in order to achieve optimum balance across the whole refining process. Hot metal pre-treatment generally includes desiliconisation, dephosphorisation and desulfurisation processes. Because each process has different favourable conditions in operational as well as thermodynamic terms, iron- and steelmaking companies have been adopting their own sequences and procedures.

The development of pre-treatment technologies has been accelerated by many valuable experimental, industrial and even theoretical studies. This is particularly true for the changes made in the dephosphorisation process [1,2], in terms of flux composition [3,4] and in thermodynamic and kinetic modelling [5,6]. Simultaneous desulfurisation and dephosphorisation of the hot metal was suggested by careful analyses of the oxygen potential and flux composition [7-11]. Based on the high oxygen supply rates and lime injection, the dephosphorisation in the converter became advantageous, and, currently, the process is widely used in many steelmaking mills [12-15]. Nonetheless, a preliminary dephosphorisation in the transfer vessel may be still required in the production of ultra-low phosphorus grade steel. Moreover, the dephosphorisation within the converter cannot be applied to the production of high-alloy steel using hot metal, due to the oxidation of the alloy elements. 
However, hot metal transfer vessels such as open ladles or torpedoes generally have low stirring capability and insufficient free board. To overcome these limitations, solid and gaseous oxygen sources can be used, by supplying them onto the surface or injecting them into the hot metal. Dephosphorisation can be carried out by either injected oxygen during flotation or slag-metal reaction with a top flux. While the phosphorus removal in the top flux is a 'permanent' reaction, the dephosphorisation with injected oxygen is described as 'transitory' reaction, because the phosphorus oxidised by the injected oxygen may be readily reduced by carbon in the hot metal. An optimal control of both reactions is of primary importance for effective dephosphorisation [16].

Various kinds of oxygen sources can be supplied in different ways to perform the dephosphorisation in the transfer vessel; moreover, desiliconisation should be carried out in advance and also at the same time as the dephosphorisation. Therefore, it is necessary to understand in detail the properties of the solid and gaseous oxygen sources, as well as the mechanisms of the transitory and permanent reactions during desiliconisation and dephosphorisation. In this study, the influences of the oxygen source type and supply method on the desiliconisation and dephosphorisation processes are investigated by laboratory-scale experiments; moreover, we discuss the reaction mechanisms involved in these processes.

\section{Materials and Methods}

Three series of laboratory experiments were carried out to investigate the effects and roles of various oxygen sources in the desiliconisation and dephosphorisation processes.

Dephosphorisation experiments using various solid oxygen sources were carried out in a high-frequency induction furnace equipped with a vacuum chamber (Hyundai Electronics, Seoul, Korea) as shown in Figure 1. Several types of raw materials (sintered return ore, scale briquette and fine mill scale) were used as solid oxygen materials. Their composition and sizes are summarised in Table 1; each material was prepared for the laboratory-scale hot metal dephosphorisation by crushing it into similar size $(\sim 1 \mathrm{~mm})$ and drying at $373 \mathrm{~K}$ for $6 \mathrm{~h}$. Electrolytic steel, graphite and reagent-grade iron phosphide were charged in a $\mathrm{MgO}$ crucible with inner diameter of $55 \mathrm{~mm}$, to prepare a hot metal with composition C 4.2 wt. \%, Si 0.15 wt. \%, P 0.1 wt. \%. After evacuating the chamber at least three times, deoxidised Ar gas, previously purified with sodium hydroxide and magnesium perchlorate, was introduced into the chamber and injected into the hot metal through an immersed alumina lance, at a rate of 0.4 SLPM (standard litres per minute at $273.15 \mathrm{~K}$ and $101.325 \mathrm{kPa}$ ). The temperature was then increased to $1623 \mathrm{~K}$, using a predetermined pattern and controlled by a thermocouple placed under a carbon crucible. Once about $0.8 \mathrm{~kg}$ of hot metal was completely molten, an initial metal sample $(t=0)$ was collected; the purified Ar was then injected into the hot metal through an immersed alumina lance, at a rate of 0.4 SLPM. Thereafter, the solid oxygen material was added, together with $\mathrm{CaO}$ powder, from the top of the furnace. The addition was carried out every $10 \mathrm{~min}$ for a total of four times over $40 \mathrm{~min}$. The total amount of solid oxygen was estimated in such a way as to achieve an acceptable composition of the hot metal ( $\mathrm{Si}$, trace; $\mathrm{P}, 0.02 \mathrm{wt}$. \%), assuming constant desiliconisation and dephosphorisation efficiencies during the experiment. Various operational data from hot metal pre-treatment plants were used to estimate the values of the desiliconisation and dephosphorisation efficiencies (60\% and 20\%, respectively). Moreover, the amount of $\mathrm{CaO}$ was determined to adjust $\%$ $\mathrm{CaO} / \% \mathrm{SiO}_{2}$ to be 3.0 . 


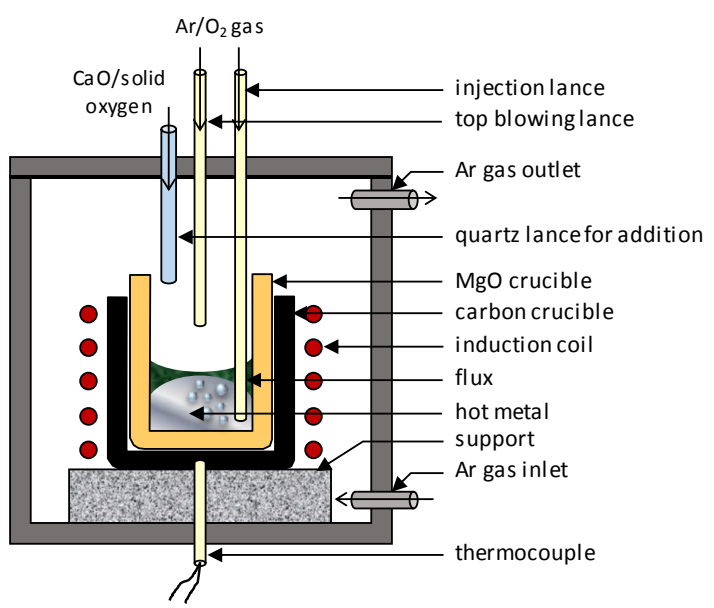

Figure 1. Schematic illustration of experimental apparatus.

Table 1. Characteristic of various solid oxygen sources considered in the present study.

\begin{tabular}{|c|c|c|c|c|c|c|c|c|c|c|}
\hline \multirow{2}{*}{ Oxygen Source } & \multicolumn{9}{|c|}{ Composition (wt. \%) } & \multirow{2}{*}{$\begin{array}{l}\text { Original } \\
\text { Size }(\mathrm{mm})\end{array}$} \\
\hline & T-Fe* & M-Fe ${ }^{*}$ & $\mathbf{O}$ & $\mathrm{FeO}$ & $\mathrm{Fe}_{2} \mathrm{O}_{3}$ & $\mathrm{SiO}_{2}$ & $\mathrm{CaO}$ & $\mathbf{P}$ & Others & \\
\hline Sintered return ore & 58.3 & - & 24.1 & 7.8 & 74.7 & 5.51 & 9.57 & 0.05 & 2.46 & $2-10$ \\
\hline Scale briquette & 73.6 & 12.8 & 22.4 & 33.7 & 49.4 & 0.80 & 0.10 & 0.02 & 0.21 & $40-50$ \\
\hline Fine mill scale & 74.5 & - & 24.9 & 63.7 & 35.8 & 0.15 & 0.18 & 0.01 & 0.12 & $5-8$ \\
\hline
\end{tabular}

* T-Fe and M-Fe stand for total Fe and metallic Fe contents, respectively.

Similar experiments were carried out to study the influence of gaseous oxygen, blown either from the top or into the hot metal, on desiliconisation and dephosphorisation. About $0.8 \mathrm{~kg}$ of hot metal in an $\mathrm{MgO}$ crucible was melted in a high-frequency induction furnace, to yield the same composition described earlier. Ar and $\mathrm{O}_{2}$ gases were blown through two alumina lances, which were placed on the top of and into the hot metal for top blowing and injection, respectively. The specific blowing conditions used with the two lances are listed in Table 2. $\mathrm{CaO}$ was added intermittently from the top of the hot metal to achieve a stable dephosphorisation reaction.

Table 2. Gas blowing conditions for hot metal desiliconisation and dephosphorisation.

\begin{tabular}{ccc}
\hline Blowing Conditions & Top Lance & Bottom Lance \\
\hline $\mathbf{1}$ & $\mathrm{O}_{2}$ 0.4 SLPM & Ar 0.4 SLPM \\
\hline $\mathbf{2}$ & $\mathrm{O}_{2}$ 0.2 SLPM, Ar 0.2 SLPM & $\mathrm{O}_{2}$ 0.2 SLPM, Ar 0.2 SLPM \\
\hline $\mathbf{3}$ & Ar 0.4 SLPM & $\mathrm{O}_{2}$ 0.4 SLPM \\
\hline
\end{tabular}

In another set of experiments in a larger furnace scale, the effects of the top-charged solid oxygen and injected gaseous oxygen on desiliconisation and dephosphorisation were compared upon injecting $\mathrm{CaO}$ into the hot metal. The injection of $\mathrm{CaO}$ powder was performed with an injection lance especially designed for upward and downward movement, as shown in Figure 2. About $200 \mathrm{~kg}$ of hot metal with the same composition was melted in a high-frequency induction furnace. In the experiments with solid oxygen, sintered return ore was dropped onto the hot metal, while $\mathrm{CaO}$ was injected with $\mathrm{Ar}$ as a carrier gas. On the other hand, in the gaseous oxygen experiments $\mathrm{CaO}$ was injected into the hot metal with dehydrated air, which played the roles of oxygen source and carrier gas. The amount of each oxygen source was adjusted to yield an equivalent amount of oxygen. 


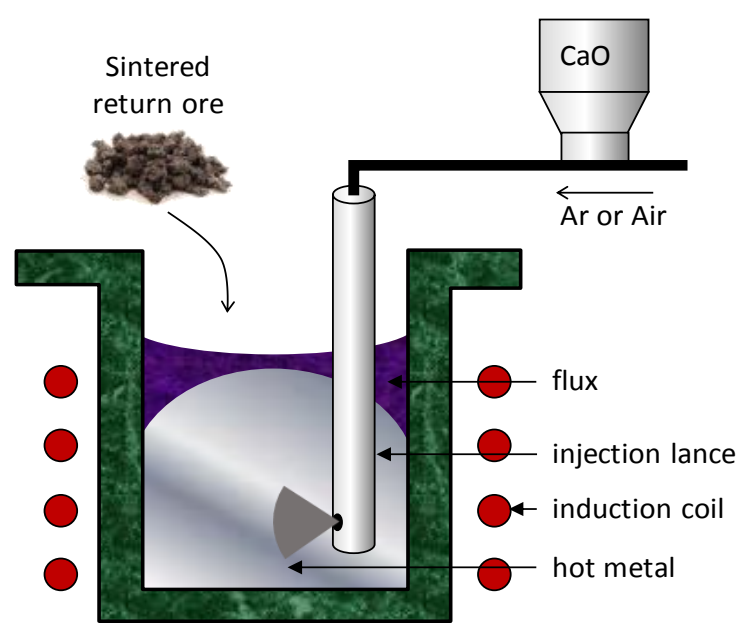

Figure 2. Schematic illustration of experimental apparatus with $\mathrm{CaO}$ injection.

In each experiment, metal samples were collected by suction every 5 min to investigate the changes in composition with time. While the carbon content in the samples was determined by combustion infrared detection using an elemental analyser (CS600, LECO Corp., Miami, FL, USA), the silicon and phosphorus contents were measured with an inductively coupled plasma optical emission spectrometer (ARCOS EOP, Spectro, Kleve, Germany).

\section{Results and Discussion}

\subsection{Desiliconisation and Dephosphorisation Behaviours of Various Solid Oxygen Materials}

Figure 3 shows the changes in the $\mathrm{C}$, Si and $\mathrm{P}$ contents in the hot metal when various types of solid oxygen material were added. Regardless of the kind of solid oxygen source, the C, Si and P contents in the hot metal were found to decrease with time. Compared to the phosphorus content in the hot metal, however, the $\mathrm{Si}$ content sharply decreased to a value as low as $0.02 \mathrm{wt}$. \% in $35 \mathrm{~min}$. Dephosphorisation appeared to be negligible in the early stages and, notably, took place when the $\mathrm{Si}$ content was less than $0.02 \mathrm{wt}$. \%. This suggests the high importance of performing the desiliconisation as rapidly as possible, in order to achieve a satisfactory dephosphorisation efficiency.

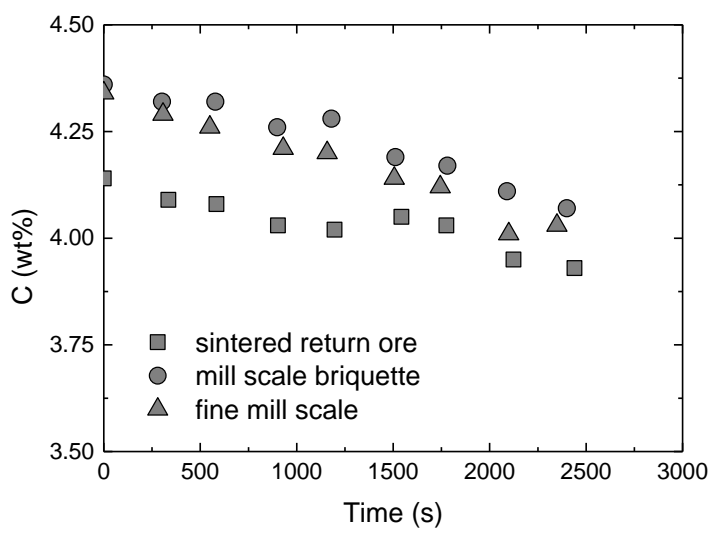

(a)

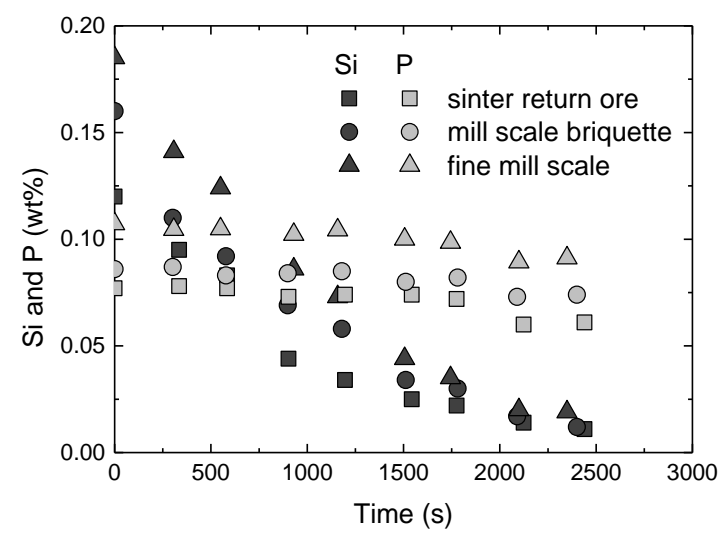

(b)

Figure 3. Changes in (a) $\mathrm{C}$ and (b) $\mathrm{Si} / \mathrm{P}$ contents of hot metal upon addition of various solid oxygen materials.

In order to quantitatively compare the effects of different solid oxygen sources, the amount of oxygen consumed for desiliconisation/dephosphorisation and the corresponding efficiencies were estimated by considering the initial contents and their preferential oxidation tendencies. Based on 
the total amount of oxygen consumed by each reaction between solid oxygen and hot metal, decarburisation occurs first, followed by desiliconisation, while dephosphorisation takes place last. Therefore, the amount of oxygen consumed for the preceding reactions should be taken into account when estimating the desiliconisation and dephosphorisation efficiencies, as shown in Equations (1) and (2).

$$
\begin{gathered}
\text { De }- \text { Si efficiency }=\frac{(\mathrm{O} \text { for } \mathrm{De}-\mathrm{Si})}{(\text { Total } \mathrm{O})-(\mathrm{O} \text { for } \mathrm{De}-\mathrm{C})} \times 100 \% \\
\text { De }- \text { P efficiency }=\frac{(\mathrm{O} \text { for } \mathrm{De}-\mathrm{P})}{(\text { Total } \mathrm{O})-(\mathrm{O} \text { for } \mathrm{De}-\mathrm{C})-(\mathrm{O} \text { forDe }-\mathrm{Si})} \times 100 \%
\end{gathered}
$$

The estimated decarburisation, desiliconisation and dephosphorisation efficiencies of the various solid oxygen materials in the whole experiment are shown in Figure 4. Compared to the changes in the C, Si and P contents in Figure 3, the reaction efficiencies of each solid oxygen material showed a significantly distinct behaviour during the experiments. Among the three types of solid oxygen materials, the highest efficiencies in all reactions were obtained for fine mill scale. Although the amounts of $\mathrm{C}, \mathrm{Si}$ and $\mathrm{P}$ removed by sintered return ore and by the other materials were comparable, sintered return ore showed the lowest efficiencies for decarburisation, desiliconisation and dephosphorisation. This difference may be attributed to the presence of higher contents of $\mathrm{Fe}_{2} \mathrm{O}_{3}$ than $\mathrm{FeO}$, which is relatively more reducible at equivalent oxygen contents in sintered return ore. A higher efficiency of fine mill scale may result in a significant reduction in the required amount of refining agents and processing time.

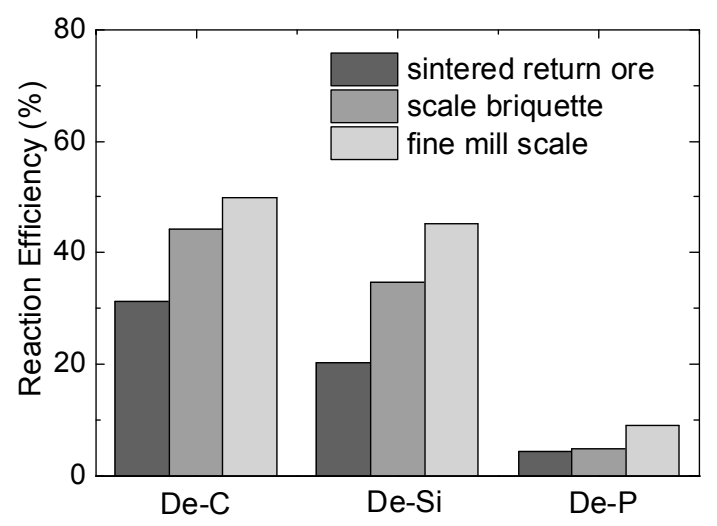

Figure 4. Decarburisation, desiliconisation and dephosphorisation reaction efficiencies of various solid oxygen materials.

\subsection{Effect of Gaseous Oxygen Supply Method on Desiliconisation and Dephosphorisation of Hot Metal}

To further investigate the effect of gaseous oxygen on the desiliconisation and dephosphorisation of the hot metal, a series of experiments with $0.8 \mathrm{~kg}$ of hot metal were carried out using different supply methods of gaseous oxygen. The detailed conditions are described in Table 2. Similar to solid oxygen, the contents of C, Si and P in the hot metal decreased with time, as shown in Figure 5, with gaseous oxygen supplied by either top blowing or injection. Regardless of how gaseous oxygen was supplied, the carbon content showed a gradual decrease. While extensive oxidation of silicon took place in the early stages of oxygen blowing, the dephosphorisation of the hot metal was found to be far from a satisfactory level. In particular, when gaseous oxygen was bottom-blown by injection, phosphorus removal was negligible compared to the removal observed with top-blown oxygen. Based on the different dephosphorisation behaviour shown in Figure 5, it could be concluded that the contribution of the transitory reaction to the hot metal dephosphorisation was relatively small, compared to that of the permanent reaction between hot metal and top slag. 


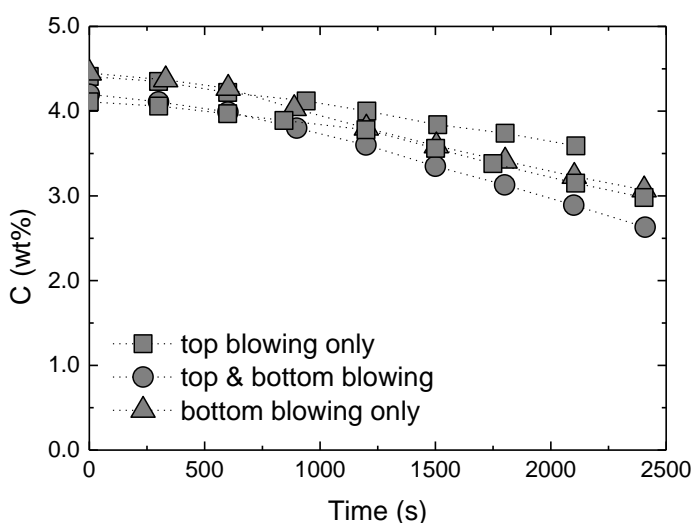

(a)

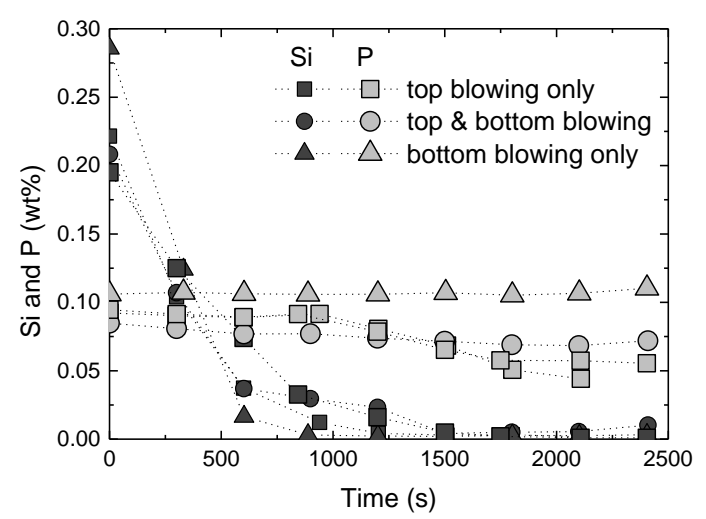

(b)

Figure 5. Changes in (a) $\mathrm{C}$ and (b) $\mathrm{Si} / \mathrm{P}$ contents of hot metal with different supply methods of gaseous oxygen.

A number of studies have focused on the permanent and transitory reactions in dephosphorisation since the 1980s [16-20]. Although in the transitory reaction the injected oxygen may oxidise phosphorus in the hot metal, phosphorus oxides are readily reduced during flotation by $\mathrm{C}$ or $\mathrm{Si}$ in the hot metal. This also implies that simultaneous $\mathrm{CaO}$ injection is necessary for $\mathrm{P}_{2} \mathrm{O}_{5}$ stabilisation. In contrast, top oxygen blowing enables active Fe oxidation, leading to the formation of a top slag with high basicity and high Fe oxide content. The higher dephosphorisation capability of top-blown oxygen compared to that of injected oxygen may be due to the permanent reaction between hot metal and top slag. When oxygen was blown onto the top surface of the hot metal, dephosphorisation became significant after about $900 \mathrm{~s}$, which corresponds to a Si content lower than $0.025 \mathrm{wt}$. \%. This confirms that a rapid desiliconisation is critical for achieving a more effective dephosphorisation.

In terms of desiliconisation of the hot metal, top- and bottom-blown oxygen showed an opposite tendency to that found for dephosphorisation. The desiliconisation rate of bottom-blown oxygen was much faster than that of top-blown oxygen. Moreover, the desiliconisation efficiency of total supplied oxygen showed a marked increase to $32.9 \%$ with injected oxygen, compared to $18.9 \%$ value obtained in the experiments with top-blown oxygen. It can be expected that the injected oxygen has a higher probability and a larger interface to react with the hot metal; furthermore, the formed Si oxide could float up to the top slag without being reduced during flotation. Therefore, it can be recommended that the gaseous oxygen is injected at the first step of the dephosphorisation (further desiliconisation of pre-desiliconised hot metal), followed by switching over to the top charging of solid oxygen for deep dephosphorisation. Of course, effective countermeasures should be considered to overcome the low dephosphorisation efficiency at higher temperature, which may result from the desiliconisation following injection of gaseous oxygen.

The desiliconisation and dephosphorisation efficiencies were compared more systematically by higher-scale experiments also involving the injection of $\mathrm{CaO}$ powder. The oxygen for desiliconisation and dephosphorisation was supplied by either top charging of iron ore or injection of dehydrated air with an equivalent oxygen amount. The changes in the C, Si and P contents of the hot metal under the different conditions are presented in Figure 6. For both types of oxygen sources, the carbon and silicon contents showed a monotonic decrease, which denotes a similar behaviour to that observed in the previous experiments. However, the dephosphorisation behaviours of the two types of oxygen were significantly different from each other. In contrast to the behaviour of top-charged solid oxygen, the dephosphorisation by injected oxygen was found to be insufficient, indicating that the $\mathrm{CaO}$ injection was essentially inadequate. To improve the dephosphorisation efficiency, direct contact with $\mathrm{CaO}$ may be required, in order to enable $\mathrm{P}_{2} \mathrm{O}_{5}$ to reach the top slag unreduced. 


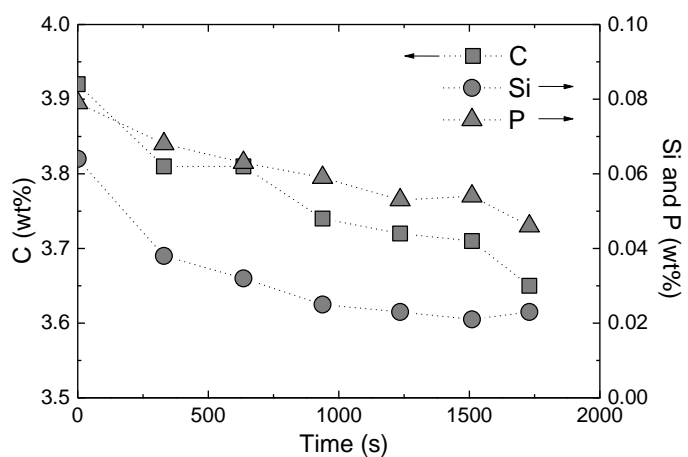

(a)

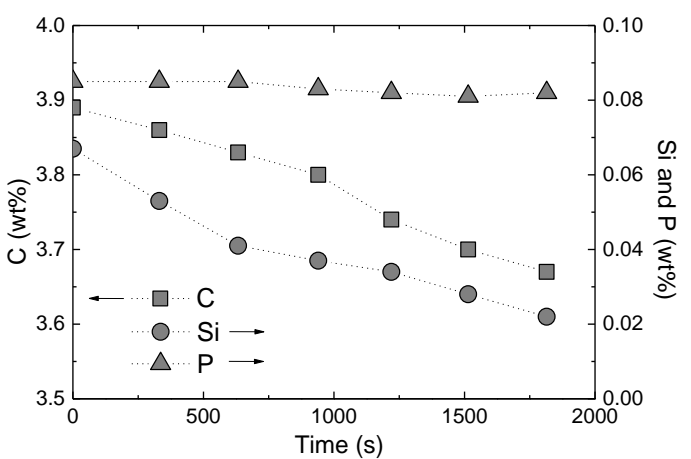

(b)

Figure 6. Changes in C, Si and P contents of hot metals subjected to different oxygen supply methods:

(a) iron ore top charging; (b) dehydrated air injection.

In order to understand the relatively low dephosphorisation ability of injected oxygen, the reaction efficiencies of desiliconisation and dephosphorisation during the experiments were evaluated, as shown in Figure 7. As mentioned earlier, the overall efficiencies of desiliconisation and dephosphorisation were higher with iron ore top charging than those with dehydrated air injection. Besides the difference in overall efficiency, it should be noted that the desiliconisation and dephosphorisation efficiencies of top-charged solid oxygen drastically decreased with time in a very similar manner. This drop of the efficiency is likely due to the increase in the top slag amount, which may hinder the active contact between top-charged solid oxygen and hot metal. On the other hand, in the experiments using air injection, the desiliconisation and dephosphorisation efficiencies behaved in the opposite way. These different behaviours reflect well the characteristics of the permanent and transitory reactions during hot metal treatment. In the transitory reaction, dephosphorisation is only feasible when phosphorus oxide can float upward without being reduced by $\mathrm{Si}$ in the hot metal. Therefore, a more effective dephosphorisation can be achieved by optimising the type and supply method of the oxygen material, based on the relationship between desiliconisation and dephosphorisation.

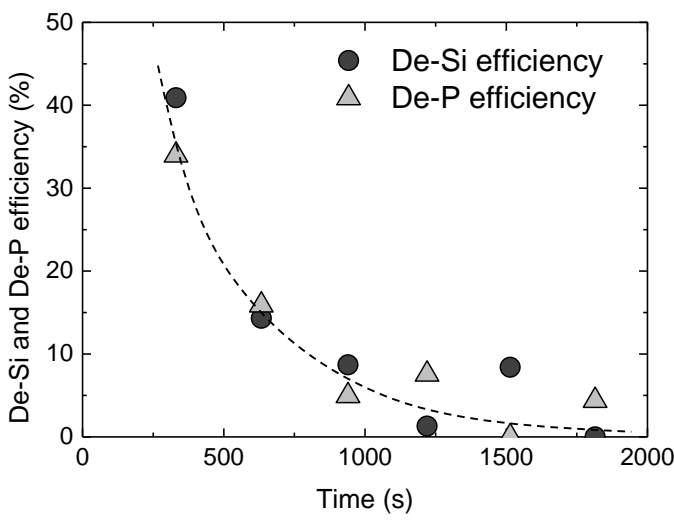

(a)

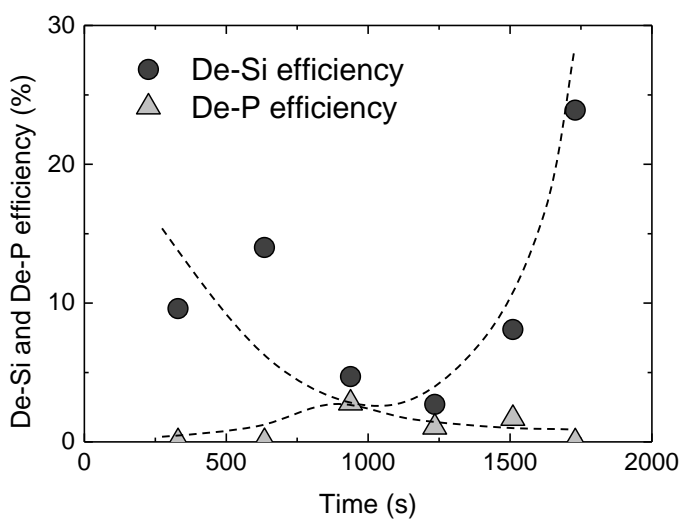

(b)

Figure 7. Changes in desiliconisation and dephosphorisation efficiencies with different oxygen supply methods: (a) iron ore top charging; (b) dehydrated air injection.

\section{Conclusions}

The effects of the oxygen source type and supply method on the hot metal desiliconisation and dephosphorisation were experimentally investigated. The reaction efficiencies achieved with injected gaseous oxygen and other oxygen sources were compared via a series of experiments. Among various types of solid oxygen materials, scale materials turned out to be more favourable than 
iron ore, mainly because of the higher FeO content. The experiments comparing the top blowing and injection methods of gaseous oxygen revealed that the injected gaseous oxygen hardly contributes to the dephosphorisation, due to the low dephosphorisation efficiency of the transitory reaction. However, desiliconisation by injected oxygen was found to be considerably effective in the early stages. These findings suggest the possibility to optimise the supply method of gaseous oxygen according to the reaction steps. In larger-scale experiments with controlled $\mathrm{CaO}$ injection, it was also observed that the dephosphorisation ability of injected gaseous oxygen was still unsatisfactory, compared to that of top-charged solid oxygen. Moreover, the permanent and transitory reactions involved in the desiliconisation and dephosphorisation processes were illustrated by the changes in their respective efficiencies. In particular, the desiliconisation and dephosphorisation reactions by injected oxygen turned out to be in a competitive relationship during the transitory reaction.

Funding: This work was supported by the Dong-A University research fund.

Acknowledgments: The author is grateful to Lee Heeho for his assistance with very complicated experiments. Valuable and stimulating advice from Suk Min-Oh is also acknowledged.

Conflicts of Interest: The author declares no conflicting interest.

\section{References}

1. Ogawa, Y.; Maruoka, N. Progress of Hot Metal Treatment Technology and Future Outlook. Tetsu Hagane J. Iron Steel Inst. Jpn. 2014, 100, 434-444. [CrossRef]

2. Iwasaki, M.; Matsuo, M. Change and Development of Steelmaking Technology. Nippon Steel Tech. Rep. 2012, 101, 89-94.

3. Guo, S.; Dong, Y.; Chen, E.; Wang, H. Dephosphorization and rephosphorization of liquid steel by lime based fluxes. Gangtie 2000, 3, 5 .

4. Yue, K.; Li, J. Dephosphorization of Hot Metal With Slag Containing CaO-Fe $\mathrm{F}_{2} \mathrm{O}_{3}$. J. Iron Steel Res. 2006, 9, 2.

5. Yang, X.; Li, J.; Chai, J.; Duan, D.; Zhang, J. A Thermodynamic Model for Predicting Phosphorus Partition between CaO-based Slags and Hot Metal during Hot Metal Dephosphorization Pretreatment Process Based on the Ion and Molecule Coexistence Theory. Metall. Mater. Trans. B 2016, 47, 2279-2301. [CrossRef]

6. Pak, J.J.; Fruehan, R.J. Dynamics of the hot metal dephosphorization with $\mathrm{Na}_{2} \mathrm{O}$ slags. Metall. Trans. B 1987, 18B, 687-693. [CrossRef]

7. Nakamura, Y.; Harashima, K.; Fukuda, Y. Dephosphorization and Desulfurization of Molten 4\%C-Fe Alloy with CaO-based flux Containing Halide. Tetsu-to-Hagané 1981, 67, 2138-2144. [CrossRef]

8. Inoue, H.; Shigeno, Y.; Tokuda, M.; Ohtani, M. On Simultaneous Dephosphorization and Desulphurization of Pig Iron with $\mathrm{CaO}-\mathrm{CaCl}_{2}$ Fluxes. Tetsu-to-Hagané 1983, 69, 210-219. [CrossRef]

9. Taskinen, A.; Janke, D. Slag Pretreatment for Simultaneous Dephosphorization and Desulphurization of Hot Metal. Stahl Eisen 1983, 103, 491-496.

10. Umezawa, K.; Matsunaga, H.; Arima, R.; Tonomura, S.; Furugaki, I. The Influence of Operating Condition on Dephosphorization and Desulphurization Reactions of Hot Metal with Lime-based Flux. Tetsu-to-Hagané 1983, 69, 1810-1817. [CrossRef]

11. Hernandez, A.; Romero, A.; Chavez, F.; Angeles, M. Dephosphorization and desulfurization pretreatment of molten iron with $\mathrm{CaO}-\mathrm{SiO}_{2}-\mathrm{CaF}_{2}-\mathrm{FeO}-\mathrm{Na}_{2} \mathrm{O}$ slags. ISIJ Int. 1998, 38, 126-131. [CrossRef]

12. Nozaki, T.; Nakanishi, K.; Morishita, H.; Yamada, S.; Sudo, F. Characteristics of Dephosphorization in a Bottom Blown Converter and Its Application to the Preliminary Treatment of Hot Metal. Tetsu-to-Hagané 1982, 68, 1737-1743. [CrossRef]

13. Ono, H.; Masui, T.; Mori, H. Dephosphorization Kinetics of Hot Metal by Lime Injection with Oxygen Gas. Tetsu-to-Hagané 1983, 69, 1763-1770. [CrossRef]

14. Ogawa, Y.; Yano, M.; Kitamura, S.; Hirata, H. Development of the Continuous Dephosphorization and Decarburization Process Using BOF. Tetsu-to-Hagané 2001, 87, 21-28. [CrossRef]

15. Mukawa, S.; Mizukami, Y. Effect of Stirring Energy and Rate of Oxygen Supply on the Rate of Hot Metal Dephosphorization. ISIJ Int. 1995, 35, 1374-1380. [CrossRef]

16. Haida, O.; Takeuchi, S.; Nozaki, T.; Emi, T.; Sudo, F. Mechanism of Hot Metal Dephosphorization by Injecting Lime Base Fluxes into Bottom Blown Converter. Tetsu-to-Hagané 1982, 68, 1744-1753. [CrossRef] 
17. Kawauchi, Y.; Maede, H.; Kamisaka, E.; Satoh, S.; Inoue, T.; Naki, M. Metallurgical Characteristics of Hot Metal Desiliconization by Injecting Gaseous Oxygen. Tetsu-to-Hagané 1983, 69, 1730-1737. [CrossRef]

18. Saito, K.; Nakanishi, K.; Misaki, N.; Nakai, K.; Onishi, M. Dephosphorization of Hot Metal with Injection of Lime Bearing Fluxes in a Ladle. Tetsu-to-Hagané 1983, 69, 1802-1809. [CrossRef]

19. Inoue, T.; Yoshida, M.; Sato, H.; Yonenaka, E. De-siliconization and de-phosphorization treatment of hot metal by gaseous oxygen injection in TPC. Tetsu-to-Hagané 1985, 71, S943.

20. Roy, G.G.; Chaudhary, P.N.; Minj, R.K.; Goel, R.P. Dephosphorization of ferromanganese using $\mathrm{BaCO}_{3}$-based fluxes by submerged injection of powders: A preliminary kinetic study. Metall. Mater. Trans. B 2001, 32B, 558-561. [CrossRef]

(C) 2019 by the author. Licensee MDPI, Basel, Switzerland. This article is an open access article distributed under the terms and conditions of the Creative Commons Attribution (CC BY) license (http:/ / creativecommons.org/licenses/by/4.0/). 